\title{
The Effects of Labour Market Policies in an Economy with an Informal Sector*
}

\author{
James Albrecht ${ }^{\dagger}$ \\ Georgetown University and IZA \\ Lucas Navarro \\ ILADES-Universidad Alberto Hurtado \\ Susan Vroman \\ Georgetown University and IZA
}

July 2008

\begin{abstract}
In this paper, we build an equilibrium search and matching model of an economy with an informal sector. Our model extends Mortensen and Pissarides (1994) by allowing for ex ante worker heterogeneity with respect to formal-sector productivity. We use the model to analyse the effects of labour market policy on informal-sector and formalsector output, on the division of the workforce into unemployment, informal-sector employment and formal-sector employment, and on wages. Finally, we examine the distributional implications of labour market policy; specifically, we analyse how labour market policy affects the distributions of wages and productivities across formal-sector matches.
\end{abstract}

Running Title: Informality and Labour Market Policy

JEL Codes: E26, J64, O17

${ }^{*}$ We thank Mauricio Santamaría for stimulating conversations that inspired our interest in this topic. We also thank Bob Hussey and Fabien Postel-Vinay as well as our editor, Steve Pischke, and two anonymous referees for their helpful comments.

†Corresponding author: albrecht@georgetown.edu 


\section{Introduction}

In this paper we construct a search and matching model that we use to analyse the effects of labour market policies in an economy with a significant informal sector. What we mean by an informal sector is a sector that is unregulated and hence not directly affected by labour market policies such as severance or payroll taxes. We find that labour market policies that apply only to the formal sector nonetheless affect the size and the composition of employment in the informal sector. This is important since there is substantial economic activity in the informal sector in many economies, particularly in developing countries. Estimates for some Latin American countries put the informal sector at more than $50 \%$ of the urban work force. ${ }^{1}$ The informal sector is also important in many transition countries as well as in some developed economies. ${ }^{2}$

Although much of the literature treats the informal sector as a disadvantaged sector in a segmented labour market framework, this interpretation is not consistent with recent empirical evidence from Latin America. Under a segmented or dual labour market interpretation, one would expect jobs to be rationed in the primary sector and workers to be in the secondary or informal sector involuntarily and to be queuing for formal-sector jobs. Maloney (2004) presents evidence for several Latin American countries that challenges this view and instead interprets the informal sector as an unregulated micro-entrepreneurial sector. Similarly, using data from the Argentinian household survey, Pratap and Quintin (2006) reject the notion that labour markets are segmented in the greater Buenos Aires area, concluding that there is no evidence of a formal-sector wage premium after controlling for individual and establishment characteristics. Evidence from Mexico (Gong and Van Soest, 2002; Gong, Van Soest and Villagomez, 2004) and from Colombia (Mondragón and Peña, 2008) is also consistent with Maloney's (2004) perspective. These papers document a negative association between informal-sector employment and education level within countries; there is also a negative correlation between informality and average educational attainment across coun-

\footnotetext{
${ }^{1}$ According to Maloney (2004), the informal sector includes 30 to $70 \%$ of urban workers in Latin American countries.

${ }^{2}$ Schneider and Enste (2000) give estimates for a wide range of countries. They calculate that the informal sector accounts for 10 to 20\% of GDP in most OECD countries, 20 to 30\% in Southern European OECD countries and in Central European transition economies. They calculate that the informal sector accounts for 20 to $40 \%$ of GDP for the former Soviet Union countries and as much as $70 \%$ for some developing countries in Africa and Asia.
} 
tries (Mastalioglu and Rigolini, 2006). Finally, there are economies with relatively flexible labour markets that nonetheless have large informal sectors. ${ }^{3}$

The view of the informal sector that we take in this paper is that it is important, that it can be usefully modeled as unregulated self employment, and that whether a worker is employed in the formal or the informal sector is to some extent a matter of choice. An important determinant of the worker's choice is his or her relative productivity in the two sectors, and a more highly skilled worker is more likely to be found in the formal sector. There is, however, significant mobility between the two sectors, so we need to take into account that workers are not always in their preferred jobs. In taking this view of informality, we specifically have Latin America in mind. Our model - at least not without substantial modification - would not apply to, for example, Africa. Our assumption that a worker chooses his or her sector of employment does not mean that workers in the informal sector are as well off as those in the formal sector. As Maloney writes (2004, p.12), "to say that workers are voluntarily informally employed does not imply that they are either happy or well off. It only implies that they would not necessarily be better off in the other sector."

The model that we present in this paper is a substantial extension of Mortensen and Pissarides (1994), hereafter MP, a standard model for labour market policy analysis in a search and matching framework. ${ }^{4}$ Their model is particularly attractive for our purposes because it includes endogenous job separations. Specifically, we extend MP by (i) adding an informal sector and (ii) allowing for continuous worker heterogeneity. The second extension is what makes the first one interesting. We allow workers to differ in terms of what they are capable of producing in the formal sector. All workers have the option to take up informal-sector opportunities as these come along, and all workers are equally productive in that sector, but some workers - those who are most productive in formal-sector employment - reject informal-sector work in order to wait for a formal-sector job. Similarly, the least productive workers do not find profitable work in the formal sector. Labour market policy, in addition to its direct effects on the formal sector, changes the composition of worker types in the two sectors. A policy change can disqualify some workers from formal-sector

\footnotetext{
${ }^{3}$ Maloney (1999) presents interesting evidence for Mexico, where there is a large informal sector, even though the usual sources of wage rigidity are absent. He notes that in Mexico minimum wages are not binding, unions are more worried about employment preservation than about wage negotiations, and wages have shown downward flexibility.

${ }^{4}$ There is a substantial literature that analyzes the equilibrium effects of labour market policies in developed economies using a search and matching framework, e.g., Mortensen and Pissarides (2003).
} 
employment; similarly, some workers accept informal-sector work who would not have done so earlier. Labour market policy thus affects the mix of worker types in the two sectors. These compositional effects, along with the associated distributional implications, are what our heterogeneous-worker extension of MP buys.

We use our model to analyse the effects of labour market policy in an economy with an informal sector. We focus on the effects of severance taxes and payroll taxes because these are particularly important in Latin America. ${ }^{5}$ We do this by solving our model numerically and performing policy experiments. We start from a baseline case that represents a composite Latin American economy. We then carry out two sets of simulations. We first vary the payroll tax rate, holding the severance tax at its baseline level, and then reverse the exercise, varying the severance tax while holding the payroll tax rate constant. Second, we vary the two taxes simultaneously, holding tax revenues constant at the baseline level. We investigate the effects of these changes on aggregate labour-market outcomes and on formal-sector wage inequality. We also display the steady-state distributions of productivity and wages across formal-sector jobs.

Holding the payroll tax rate constant, we find that the severance tax reduces the rate at which workers find formal-sector jobs but at the same time increases average employment duration in the formal sector. There are also compositional effects - fewer workers take formal-sector jobs and fewer workers reject informal-sector jobs. The net effect is that unemployment among workers who take formal-sector jobs falls, as does aggregate unemployment. Holding the severance tax constant, a payroll tax has somewhat different effects. It also reduces the rate at which workers find formal-sector jobs, but, unlike the severance tax, it decreases average employment duration in the formal sector. Again, there are compositional effects. As with the severance tax, fewer workers reject the informal sector, and more workers reject the formal sector. Unemployment among workers who take formal-sector jobs increases, as does aggregate unemployment. Even though severance taxation decreases unemployment while payroll taxation increases unemployment in our policy experiments, severance taxation is the more distorting policy. A severance tax has strong negative effects on productivity because firms keep jobs intact even when productivity is low to avoid paying the tax. On the other hand, payroll taxation has a positive effect on formal-sector productivity. Only high-productivity matches are worth sustaining in the presence of a payroll tax.

\footnotetext{
${ }^{5}$ See Heckman and Pagés (2004). For the specific case of Colombia, see Kugler (1999) and Kugler and Kugler (2008).
} 
Both policies lead to a fall in net output, but the severance tax has a much stronger effect. In fact, payroll taxation is welfare improving in our simulations in the sense that raising this tax increases the sum of net output and tax revenues. There are two reasons for this. First, increasing the payroll tax undoes some of the worst effects of severance taxation; in particular, payroll taxation partially reverses the incentive that severance taxation gives to prolong unproductive matches. Second, there is an inefficiency in the laissez faire equilibrium - the incentive to turn down informal-sector opportunities in order to wait for a formal-sector job is too strong for some workers. Taxation, especially payroll taxation, works to correct this inefficiency. When we vary the two taxes simultaneously holding total tax revenue constant, in particular, as we increase the severance tax and decrease the payroll tax rate holding tax revenue at the baseline level, unemployment decreases, employment duration rises, and formal-sector productivity falls. This is as expected since an increase in the severance tax and a decrease in the payroll tax each move these variables in the same direction, holding the other tax constant. To the extent that the two tax changes have opposing effects, e.g., an increase in the severance tax moves workers from the formal to the informal sector while a decrease in the payroll tax has the opposite effect, the severance tax effects dominate. Finally, we look at the effect of varying the two taxes simultaneously on formal-sector wage inequality. An increase in the severance tax coupled with a decrease in the payroll tax reduces wage dispersion in the formal sector.

There are several other recent papers that model the effects of labour market policy in economies with an informal sector. Many of these adopt the view that the informal sector is illegal, with tax evasion and noncompliance with legislation as its identifying characteristics. These papers focus on the disutility of participation in the underground economy and analyse the effect of monitoring and punishment on informality. ${ }^{6}$

Another approach is the one taken by Satchi and Temple (2006) and Zenou (2008). Workers are assumed to be homogeneous, and a central issue in these papers is why identical workers are paid a higher wage in the formal sector than in the informal sector. Both papers assume that the informal sector is perfectly competitive but that there are matching frictions

\footnotetext{
${ }^{6}$ See, for example, Fugazza and Jacques (2004), Kolm and Larsen (2004), Boeri and Garibaldi (2007), and Bosch (2007). Laing, et al. (2005) provides an interesting mirror image of this literature. They use a search-matching model to analyse rural-urban inequality in China. Under the huku system, a fraction of the workforce is prohibited from leaving the rural sector. These workers can and do, however, seek urban work illegally.
} 
in the formal sector. There is no unemployment per se in these models; rather, workers in the informal sector search for formal-sector jobs, i.e., queue for formal-sector jobs. Satchi and Temple (2006) examine how growth affects the sizes of and outcomes in the rural, informal and formal sectors and calibrate their model to Mexican data, while Zenou (2008) focuses on the effects of policies such as unemployment compensation.

Amaral and Quintin (2006) is closer in spirit to our model in that workers in the informal sector are not queuing for formal-sector jobs. In their model, there are two worker types, unskilled and skilled. Managers choose between financing their operations out of savings versus borrowing. In order to borrow, a firm must operate in the formal sector, where debt contracts can be enforced. Operating in the formal sector thus gives greater access to capital; on the other hand, firms operating in the informal sector are not taxed. Assuming that unskilled labour is a substitute for capital, while skilled labour is a complement, workers with formal-sector jobs are paid higher wages and are more productive than workers in the informal sector. Thus, the more productive workers sort themselves into the formal sector. Relative to Amaral and Quintin (2006), our approach offers two advantages. First, we allow for matching frictions, so we can analyse the unemployment effects of labour market policy. Second, we allow for a continuum of worker types, as opposed to simply unskilled versus skilled. Taken together, these two assumptions (matching frictions and a continuum of types) lead to imperfect sorting. On average, workers in the formal sector are more productive than their informal-sector counterparts. This allows us to give a rich distributional analysis of the effects of labour market policy.

Finally, although their model does not address informality per se, Dolado et al. (2007) is also closely related to our work. They construct a search and matching model to analyse the effect of targeted severance taxes. They assume that vacancies can be filled with either high-skill or low-skill workers. When a worker and a vacancy meet, an idiosyncratic match productivity is realised, and the distribution of match productivity for high-skill workers stochastically dominates the one for low-skill workers. Relative to Dolado et al. (2007), our approach has the advantage of allowing for a continuous distribution of worker types as well, of course, as being explicitly focused on informal-sector issues. ${ }^{7}$

In the next section, we describe our model and prove the existence of equilibrium. Section

\footnotetext{
${ }^{7}$ Our model is also related to the macro literature that introduces home (nonmarket) production into growth models (Gollin et al., 2004; Parente et al., 2000) and RBC models (Benhabib et al., 1991) in the sense that our informal sector could be reformulated as a home production sector.
} 
3 is devoted to our policy experiments. Our simulations give a qualitative sense for the properties of our model as well as a quantitative sense for the impact of the policies. Finally, Section 4 concludes.

\section{Model}

Our model is an extension of Mortensen and Pissarides (1994). As such, we work in continuous time and assume that workers are risk neutral, infinitely lived, and discount the future at rate $r$. We model labour market frictions using a matching function and assume that when an unemployed worker and a vacancy meet, they match if and only if the joint surplus from the match exceeds the sum of the values they would get were they unmatched. This joint surplus is then split via Nash bargaining. There is free entry of vacancies, so that in equilibrium, the value of maintaining a vacancy equals zero. Match productivity is subject to idiosyncratic shocks, and the rate of job destruction is endogenous.

We extend the MP model in two ways. First, we allow for an informal sector. We keep our treatment of this sector as simple as possible. A worker in an informal-sector job receives flow income $y_{0}$, which is the same for all workers. Opportunities to work in the informal sector arrive to the unemployed at exogenous Poisson rate $\alpha$, and employment in this sector ends at exogenous Poisson rate $\delta$. Finally, we assume that employment in the informal sector precludes search for a formal-sector job; i.e., there are no direct transitions from the informal to the formal sector (nor are there direct transitions in the opposite direction). These simplifying assumptions can be relaxed, albeit at the cost of algebraic complication.

Second, we assume that workers differ in their maximum productivities in formal-sector jobs. In particular, we assume that worker type (maximum productivity) is distributed across a unit measure of workers according to the continuous density $f(y), 0 \leq y \leq 1$. A worker starts a formal-sector job at his or her maximum productivity, $y$, and match productivity is then subject to idiosyncratic shocks, which change the current level of productivity on that job to a new level, $y^{\prime} .8$ The surplus from a formal-sector match depends both on the current productivity of the match and on the worker's type and, as in MP, we assume the wage is continuously renegotiated, including when the match productivity changes. Thus

\footnotetext{
${ }^{8}$ Alternatively, we could assume that initial match productivity is a draw from the shock distribution as is done, for example, in Dolado et al. (2007). This is inessential - the key point of our specification is that a worker of type $y$ can never produce more than $y$ in a formal-sector match.
} 
the wage, $w\left(y^{\prime}, y\right)$, also depends on both the current productivity and the worker's type. Job destruction is endogenous - a match ends when it is in the mutual interest of the worker and firm to do so.

Since we are particularly interested in analysing the effects of severance and payroll taxes, we augment our model to include those policies. The introduction of a payroll tax is straightforward, but the introduction of a severance tax requires us to distinguish between the initial negotiation between a worker and a firm and subsequent negotiations. In the initial negotiation, if bargaining breaks down, the firm does not have to pay a severance tax, but in subsequent renegotiations, the firm's outside option must include the severance tax. This implies that with a severance tax, the initial wage negotiated between the firm and a worker of type $y$, which we denote by $w(y)$, differs from subsequent wages negotiated between the firm and that worker when the worker's current productivity level $y^{\prime}=y$, i.e., $w(y, y) \cdot 9$

The details of the productivity shock process are as follows. Consider a worker of type $y$ in a formal-sector job. Shocks to the productivity of this worker's match, which arrive at exogenous Poisson rate $\lambda$, are iid draws from a continuous density $\frac{g\left(y^{\prime}\right)}{G(y)}$ for $0 \leq y^{\prime} \leq y$. The restriction on the range of $y^{\prime}$ (and the corresponding normalisation by $G(y)$ ) reflects our assumption that a worker's current productivity can never exceed his or her type. ${ }^{10}$ When a shock occurs, there are two possibilities to consider. First, if the realised value of the shock is sufficiently low, the match breaks up. Here "sufficiently low" is defined in terms of an endogenous reservation productivity, $R(y)$, which depends on the worker's type. Thus, with probability $\frac{G(R(y))}{G(y)}$, a shock ends worker $y^{\prime}$ 's match. Second, if $R(y) \leq y^{\prime} \leq y$, the productivity of the match changes to $y^{\prime}$. That is, with probability $1-\frac{G(R(y))}{G(y)}$, the match continues after a shock, but at the new productivity level and with the corresponding renegotiated wage. An important twist in our model is that different worker types have different reservation productivities; that is, instead of a single reservation productivity, $R$, as in MP, there is an equilibrium reservation productivity schedule, $R(y)$.

\footnotetext{
${ }^{9}$ See the discussion in Mortensen and Pissarides (1999).

${ }^{10}$ In an earlier version of the paper, we assumed that shocks were random draws from $g\left(y^{\prime}\right)$ for $0 \leq y^{\prime} \leq 1$. When the realized shock was such that $y^{\prime}>y$, we reset the productivity of the match to $y$. This specification gives qualitatively similar results.
} 


\section{$2.1 \quad$ Workers}

The worker side of the model is a straightforward extension of MP. A worker can be in one of four states: (i) unemployed, (ii) employed in the informal sector, (iii) employed as a new hire (outsider) in the formal sector with wage $w(y)$, or (iv) employed in the formal sector as an insider with wage $w\left(y^{\prime}, y\right)$. Unemployment is the residual state in the sense that workers whose employment in either an informal-sector or a formal-sector job ends flow back into unemployment. Unemployed workers receive $b$, which is interpreted as the flow income equivalent to the value of leisure. As mentioned above, informal-sector opportunities arrive at exogenous rate $\alpha$ and generate a flow income of $y_{0}$. Formal-sector opportunities arrive at endogenous rate $m(\theta)$, where the matching (or meeting) function, $m(\theta)$, has standard properties. ${ }^{11}$ It is important to note that not all workers are "qualified" for formal-sector work. There is a threshold $y^{*}$ (to be determined in equilibrium) such that workers with $y<y^{*}$ do not find it worthwhile to take formal-sector jobs. Similarly, there is a threshold $y^{* *}$ (also determined in equilibrium) such that workers with $y>y^{* *}$ never take informalsector opportunities. The opportunity cost of exiting unemployment, and thus temporarily giving up the possibility of finding formal-sector work, is too high for these workers. Workers are thus partitioned into three groups, (i) $0 \leq y<y^{*}$, i.e., low-productivity workers who never take formal-sector jobs, (ii) $y^{*} \leq y \leq y^{* *}$, i.e., medium-productivity workers who accept any employment opportunity that comes along, whether it be informal or formal, and (iii) $y^{* *}<y \leq 1$, i.e., high-productivity workers who never take informal-sector jobs. ${ }^{12}$

Let $U(y)$ be the value of unemployment for a worker of type $y, N_{0}(y)$ be the value of informal-sector employment for this type of worker, $N_{1}(y)$ be the initial value of employment for a worker of type $y$, and $N_{1}\left(y^{\prime}, y\right)$ be the value of employment for a worker of type $y$ in a match that has experienced one or more shocks and has current productivity $y^{\prime}$. The flow

\footnotetext{
${ }^{11}$ These are (i) $m(\theta)$ is increasing in $\theta$, (ii) $m(\theta) / \theta$ is decreasing in $\theta$, (iii) $\lim _{\theta \rightarrow 0} m(\theta)=0$ and $\lim _{\theta \rightarrow \infty} m(\theta)=\infty$, and (iv) $\lim _{\theta \rightarrow 0} m(\theta) / \theta=\infty$ and $\lim _{\theta \rightarrow \infty} m(\theta) / \theta=0$.

${ }^{12}$ We assume purely random search. That is, unemployed workers simply bump into informal-sector opportunities and formal-sector vacancies every now and then. This means that workers of type $y<y^{*}$ congest the formal-sector market. Alternatively, we could assume that these workers only look for informalsector opportunities and redefine $\theta$ to only include workers seeking formal-sector employment. This would not affect our qualitative conclusions.
} 
value of unemployment for a worker for type $y$ is ${ }^{13}$

$$
r U(y)=b+\alpha \max \left[N_{0}(y)-U(y), 0\right]+m(\theta) \max \left[N_{1}(y)-U(y), 0\right]
$$

This worker receives a flow utility of $b$ while unemployed. At the rate $\alpha$, the worker meets an informal-sector opportunity and, if it is taken, realises a capital gain of $N_{0}(y)-U(y)$. At the rate $m(\theta)$, the worker meets a formal-sector vacancy and, if the job is taken, realises a capital gain of $N_{1}(y)-U(y)$. The flow value of taking an informal-sector job is

$$
r N_{0}(y)=y_{0}+\delta\left(U(y)-N_{0}(y)\right)
$$

while the flow value of a formal-sector job depends on whether the worker is an outsider or insider. These values are

$$
\begin{aligned}
r N_{1}(y) & =w(y)+\lambda \frac{G(R(y))}{G(y)}\left(U(y)-N_{1}(y)\right)+\lambda \int_{R(y)}^{y}\left(N_{1}(x, y)-N_{1}(y)\right) \frac{g(x)}{G(y)} d x \\
r N_{1}\left(y^{\prime}, y\right) & =w\left(y^{\prime}, y\right)+\lambda \frac{G(R(y))}{G(y)}\left(U(y)-N_{1}\left(y^{\prime}, y\right)\right)+\lambda \int_{R(y)}^{y}\left(N_{1}(x, y)-N_{1}\left(y^{\prime}, y\right)\right) \frac{g(x)}{G(y)} d x,
\end{aligned}
$$

where the final two terms in these expressions reflect our assumptions about the shock process.

\section{$2.2 \quad$ Firms}

Next, consider the vacancy-creation problem faced by a formal-sector firm. The value functions for a filled job must take into account severance and payroll taxes since we assume these are nominally paid by employers. Let $V$ be the value of creating a formal-sector vacancy, $J(y)$ be the initial value of filling a job with a worker of type $y$, and $J\left(y^{\prime}, y\right)$ be the value of employing a worker of type $y$ in a match with current productivity $y^{\prime}$. The latter two values can be written as

\footnotetext{
${ }^{13}$ This Bellman equation, like all others in the paper, is the one anticipated to hold in steady state.
} 


$$
\begin{aligned}
r J(y) & =y-w(y)(1+\tau)+\lambda \frac{G(R(y))}{G(y)}(V-J(y)-s)+\lambda \int_{R(y)}^{y}(J(x, y)-J(y)) \frac{g(x)}{G(y)} d x \\
r J\left(y^{\prime}, y\right) & =y^{\prime}-w\left(y^{\prime}, y\right)(1+\tau)+\lambda \frac{G(R(y))}{G(y)}\left(V-J\left(y^{\prime}, y\right)-s\right)+\lambda \int_{R(y)}^{y}\left(J(x, y)-J\left(y^{\prime}, y\right)\right) \frac{g(x)}{G(y)} d x .
\end{aligned}
$$

A firm that employs a worker of type $y$ initially receives flow output $y$ and pays a wage of $w(y)$. After a shock that changes the match productivity to $y^{\prime}$, the firm receives flow output $y^{\prime}$ and pays a wage of $w\left(y^{\prime}, y\right)$. Wages are taxed at rate $\tau$. The final two terms in these value functions again reflect our assumptions about the shock process. At rate $\lambda$, a productivity shock arrives. With probability $\frac{G(R(y))}{G(y)}$, the job ends, and the firm pays severance tax $s$ and suffers a capital loss of either $V-J(y)-s$ or $V-J\left(y^{\prime}, y\right)-s$. If the realised shock $x$ falls in the interval $[R(y), y]$, the value of the match changes to $J(x, y)$. Note that for simplicity, we assume that tax receipts are "thrown into the ocean," i.e., used for purposes outside the model.

The value of a vacancy is defined by

$$
r V=-c+\frac{m(\theta)}{\theta} E \max [J(y)-V, 0]
$$

This expression reflects the assumption that match productivity initially equals the worker's type and that the initial bargain between the worker and firm does not include the severance tax as a part of the firm's outside option. The expectation in this expression is taken over the distribution of $y$ among the unemployed. A firm does not know in advance what type of worker it will meet. It may, for example, meet a worker of type $y<y^{*}$, in which case it is not worth forming the match. If the worker is of type $y \geq y^{*}$, the match forms, but the job's value depends, of course, on the worker's type. Finally, note that in computing the expectation, we need to account for contamination in the unemployment pool. That is, the distribution of $y$ among the unemployed, in general, differs from the corresponding population distribution. We deal with this complication below in the subsection on steady-state conditions.

As usual in this type of model, the fundamental equilibrium condition is the one given by free entry of vacancies, i.e., $V=0$. Equation (1), with $V=0$, determines the equilibrium value of labour market tightness. The other endogenous objects of the model, namely, the 
wage schedules, $w(y)$ and $w\left(y^{\prime}, y\right)$, the reservation productivity schedule, $R(y)$, and the cutoff values, $y^{*}$ and $y^{* *}$ can all be expressed in terms of $\theta$.

\subsection{Wage determination and reservation productivities}

Wages are determined using the Nash bargaining assumption with an exogenous worker bargaining power parameter $\beta$. Given $V=0$, the initial wage for a worker of type $y$ solves

$$
\max _{w(y)}\left[N_{1}(y)-U(y)\right]^{\beta} J(y)^{1-\beta} .
$$

One can verify that

$$
w(y)=\frac{\beta(y-\lambda s)+(1-\beta)(1+\tau) r U(y)}{1+\tau} .
$$

That is, the initial wage is a weighted sum of the worker's type minus a term reflecting the severance tax that must eventually be paid and the worker's continuation value.

The wage $w\left(y^{\prime}, y\right)$ for a type $y$ worker producing at $y^{\prime}$ solves

$$
\max _{w\left(y^{\prime}, y\right)}\left[N_{1}\left(y^{\prime}, y\right)-U(y)\right]^{\beta}\left[J\left(y^{\prime}, y\right)-(-s)\right]^{1-\beta} .
$$

This wage function can be written as

$$
w\left(y^{\prime}, y\right)=\frac{\beta\left(y^{\prime}+r s\right)+(1-\beta)(1+\tau) r U(y)}{1+\tau} .
$$

This insider wage is higher than the outsider wage for a current productivity of $y$ because the severance tax worsens the firm's bargaining position.

Formal-sector matches are destroyed when a sufficiently unfavorable productivity shock is realised. The reservation productivity $R(y)$ is defined by the zero-surplus condition,

$$
N_{1}(R(y), y)-U(y)+J(R(y), y)=-s .
$$

Given the surplus sharing rule, this is equivalent to

$$
J(R(y), y)=-s .
$$

Substitution gives

$$
R(y)=\frac{(r+\lambda) G(y)((1+\tau) r U(y)-r s)-\lambda\left(\int_{R(y)}^{y}(1-G(x)) d x-(1-G(y)) y\right)}{r G(y)+\lambda} .
$$


For any fixed value of $y$, this is analogous to the reservation productivity in MP. This equation makes it clear that $s$ shifts the $R(y)$ schedule down, while $\tau$ shifts it up.

An interesting question is how the reservation productivity varies with $y$. On the one hand, the higher is a worker's maximum potential productivity, the better are his or her outside options. That is, $U(y)$ is increasing in $y$. This suggests that $R(y)$ should be increasing in its argument. On the other hand, a "good match gone bad" retains its upside potential. The final term in equation (2), which can be interpreted as a labour-hoarding effect, is decreasing in $y$. This suggests that $R(y)$ should be decreasing in $y$. As will be seen below, once we solve for $U(y)$, which of these terms dominates depends on parameters.

\subsection{Unemployment values and cutoff productivities}

In order to solve for the wages and reservation productivities, we need expressions for the unemployment values and the cutoff productivities. Recall that workers with $y<y^{*}$ work only in the informal sector, workers with $y^{*} \leq y \leq y^{* *}$ accept both informal-sector and formal-sector jobs, and workers with $y>y^{* *}$ accept only formal-sector jobs. Thus $y^{*}$ is defined by the condition that a worker of type $y^{*}$ be indifferent between unemployment and a formal-sector offer, and $y^{* *}$ is defined by the condition that a worker of type $y^{* *}$ be indifferent between unemployment and an informal-sector offer.

For a worker of type $y \in\left[y^{*}, y^{* *}\right]$, the value of unemployment is given by

$$
r U(y)=b+\alpha\left[N_{0}(y)-U(y)\right]+m(\theta)\left[N_{1}(y)-U(y)\right] .
$$

The condition that $N_{1}\left(y^{*}\right)=U\left(y^{*}\right)$ then implies

$$
r U\left(y^{*}\right)=b+\alpha\left[N_{0}\left(y^{*}\right)-U\left(y^{*}\right)\right]
$$

and substitution gives

$$
r U\left(y^{*}\right)=\frac{b(r+\delta)+\alpha y_{0}}{r+\alpha+\delta} .
$$

Note that $r U(y)$ takes this value for all $y \leq y^{*}$ and that this value does not depend on $\theta$. A worker who is on the margin between accepting and rejecting formal-sector jobs does not benefit when these jobs become easier to find. Setting $U\left(y^{*}\right)$ equal to $N_{1}\left(y^{*}\right)$ gives

$$
y^{*}=(1+\tau) \frac{b(r+\delta)+\alpha y_{0}}{r+\alpha+\delta}+\frac{\lambda}{G\left(y^{*}\right)} s-\frac{\lambda}{(r+\lambda) G\left(y^{*}\right)} \int_{R\left(y^{*}\right)}^{y^{*}}[1-G(x)] d x .
$$


Since $R\left(y^{*}\right)$ does not depend on $\theta$ (because $r U\left(y^{*}\right)$ does not depend on $\theta$ ), neither does $y^{*}$.

To find $y^{* *}$ we set $N_{0}\left(y^{* *}\right)=U\left(y^{* *}\right)$, which implies that

$$
r U\left(y^{* *}\right)=b+m(\theta)\left[N_{1}\left(y^{* *}\right)-U\left(y^{* *}\right)\right] .
$$

In addition, setting $U\left(y^{* *}\right)=N_{0}\left(y^{* *}\right)$ implies that $r U\left(y^{* *}\right)=y_{0}$, so substitution gives

$$
N_{1}\left(y^{* *}\right)=\frac{(r+m(\theta)) y_{0}-r b}{r m(\theta)}
$$

Substituting for $N_{1}\left(y^{* *}\right)$ and solving gives

$$
y^{* *}=\frac{(1+\tau)\left(r G\left(y^{* *}\right)+\lambda\right)}{\beta m(\theta) G\left(y^{* *}\right)}\left(y_{0}-b\right)+(1+\tau) y_{0}+\frac{\lambda}{G\left(y^{* *}\right)} s-\frac{\lambda}{(r+\lambda) G\left(y^{* *}\right)} \int_{R\left(y^{* *}\right)}^{y^{* *}}[1-G(x)] d x .
$$

Since $U(y)$ is increasing in $y$ for all $y \geq y^{*}$ and since $r U\left(y^{* *}\right)>r U\left(y^{*}\right)$, it follows that $y^{* *}>y^{*}$ as we have assumed.

While $r U(y)$ has a simple form that does not depend on $y$ or on taxes when $y \leq y^{*}$ and $y=y^{* *}$, it is more complicated at other values of $y$. For $y^{*} \leq y<y^{* *}$, we have

$$
r U(y)=\frac{\left(b(r+\delta)+\alpha y_{0}\right)(r G(y)+\lambda)+\frac{\beta(r+\delta) m(\theta)}{(1+\tau)}\left(G(y) y-s \lambda+\frac{\lambda}{(r+\lambda)} \int_{R(y)}^{y}[1-G(x)] d x\right)}{(r+\alpha+\delta)(r G(y)+\lambda)+\beta G(y)(r+\delta) m(\theta)}
$$

and for $y \geq y^{* *}$, we have

$$
r U(y)=\frac{b(r G(y)+\lambda)+\frac{\beta m(\theta)}{(1+\tau)}\left(G(y) y-\lambda s+\frac{\lambda}{(r+\lambda)} \int_{R(y)}^{y}[1-G(x)] d x\right)}{\lambda+(r+\beta m(\theta)) G(y)} .
$$

Note that the two expressions would be identical if the informal sector did not exist, that is, were $\alpha=\delta=0$.

Given the expression for $R(y)$, equation (2), the differing forms for $r U(y)$ mean that the form of $R(y)$ differs for medium- and high-productivity workers. For any fixed value of $\theta$, equation (2) has a unique solution for $R(y)$. One can also check, given a unique schedule $R(y)$, that equations (3) and (4) imply unique solutions for the cutoff values, $y^{*}$ and $y^{* *}$, respectively. 


\section{$2.5 \quad$ Steady-state conditions}

The model's steady-state conditions allow us to solve for the unemployment rates for the various worker types. Let $u(y)$ be the fraction of time a worker of type $y$ spends in unemployment, let $n_{0}(y)$ be the fraction of time that this worker spends in informal-sector employment, and let $n_{1}(y)$ be the fraction of time that this worker spends in formal-sector employment. Of course, $u(y)+n_{0}(y)+n_{1}(y)=1$.

Workers of type $y<y^{*}$ flow back and forth between unemployment and informal-sector employment. There is thus only one steady-state condition for these workers, namely, that flows out of and into unemployment must be equal,

$$
\alpha u(y)=\delta(1-u(y))
$$

For $y<y^{*}$ we thus have

$$
u(y)=\frac{\delta}{\delta+\alpha}, \quad n_{0}(y)=\frac{\alpha}{\delta+\alpha}, \quad n_{1}(y)=0 .
$$

There are two steady-state conditions for workers with $y^{*} \leq y \leq y^{* *}$, (i) the flow out of unemployment to the informal sector equals the reverse flow and (ii) the flow out of unemployment into the formal sector equals the reverse flow,

$$
\begin{aligned}
\alpha u(y) & =\delta n_{0}(y) \\
m(\theta) u(y) & =\lambda \frac{G(R(y))}{G(y)}\left(1-u(y)-n_{0}(y)\right) .
\end{aligned}
$$

Combining these conditions gives

$$
\begin{aligned}
u(y) & =\frac{\delta \lambda G(R(y))}{\lambda(\delta+\alpha) G(R(y))+\delta m(\theta) G(y)} \\
n_{0}(y) & =\frac{\alpha \lambda G(R(y))}{\lambda(\delta+\alpha) G(R(y))+\delta m(\theta) G(y)} \\
n_{1}(y) & =\frac{\delta m(\theta) G(y)}{\lambda(\delta+\alpha) G(R(y))+\delta m(\theta) G(y)} .
\end{aligned}
$$

Finally, for workers with $y>y^{* *}$ there is again only one steady-state condition, namely, that the flow from unemployment to the formal sector equals the flow back into unemployment,

$$
m(\theta) u(y)=(1-u(y)) \lambda \frac{G(R(y))}{G(y)} .
$$


This implies

$$
\begin{aligned}
u(y) & =\frac{\lambda G(R(y))}{\lambda G(R(y))+m(\theta) G(y)} \\
n_{0}(y) & =0 \\
n_{1}(y) & =\frac{m(\theta) G(y)}{\lambda G(R(y))+m(\theta) G(y)} .
\end{aligned}
$$

Total unemployment is obtained by aggregating across the population,

$$
u=\int_{0}^{y^{*}} u(y) f(y) d y+\int_{y^{*}}^{y^{* *}} u(y) f(y) d y+\int_{y^{* *}}^{1} u(y) f(y) d y .
$$

\subsection{Equilibrium}

We use the free-entry condition to close the model and determine equilibrium labour market tightness. Setting $V=0$ in equation (1) gives

$$
c=\frac{m(\theta)}{\theta} E \max [J(y), 0] \text {. }
$$

To determine the expected value of meeting a worker, we need to account for the fact that the density of types among unemployed workers is contaminated. Let $f_{u}(y)$ denote the density of types among the unemployed. Using Bayes' Law,

$$
f_{u}(y)=\frac{u(y) f(y)}{u} .
$$

After some algebraic manipulation, we can express $J(y)$ as

$$
J(y)=(1-\beta)\left(\frac{y-R(y)}{r+\lambda}-s\right)
$$

so the free-entry condition can be written as

$$
c=\frac{m(\theta)}{\theta} \int_{y^{*}}^{1}(1-\beta)\left(\frac{y-R(y)}{r+\lambda}-s\right) \frac{u(y)}{u} f(y) d y .
$$

Equation (8), of course, only makes sense if its right-hand side is positive. Since $J\left(y^{*}\right)=0$ and $J(y)$ is increasing in $y$ for $y \geq y^{*}$, a necessary condition for equation (8) to have a solution is $y^{*}<1$. From equation (3), a simple sufficient condition for $y^{*}<1$ is

$$
(1+\tau) \frac{b(r+\delta)+\alpha y_{0}}{r+\alpha+\delta}+\lambda s<1
$$


If severance and/or payroll taxes are high enough, no formal-sector matches form. In that case, equation (8) cannot hold, and the only equilibrium is one in which all employment is in the informal sector. Such an equilibrium is not particularly interesting, so henceforth we assume that inequality (9) is satisfied. That is, we consider equilibria with formal-sector employment.

A steady-state equilibrium with formal-sector employment is a labour market tightness $\theta$, together with a reservation productivity function $R(y)$, unemployment rates $u(y)$, and cutoff values $y^{*}$ and $y^{* *}$ such that

(i) the value of maintaining a vacancy is zero

(ii) matches are consummated and dissolved if and only if it is in the mutual interest of the worker and firm to do so

(iii) the steady-state conditions hold.

Such an equilibrium exists if there is a $\theta$ that solves equation (8), taking into account that $R(y), u(y)$, and $u$ are all uniquely determined by $\theta$. A solution to equation (8) exists since the limit of its right-hand side is $\infty$ as $\theta \rightarrow 0$ and is 0 as $\theta \rightarrow \infty$. While it is clear that a steady-state equilibrium with formal-sector employment exists, to establish uniqueness requires showing that the right-hand side of equation (8) is monotonically decreasing in $\theta$. Labour market tightness enters into the right-hand side of equation (8) in three ways. First, $m(\theta) / \theta$ is monotonically decreasing in $\theta$ by assumption. Second, $\theta$ enters $J(y)=(1-\beta)\left(\frac{y-R(y)}{r+\lambda}-s\right)$ through its effect on the reservation productivity schedule. Since $R(y)$ is monotonically increasing in $\theta$ for all $y>y^{*}$, the value of a filled job, $J(y)$ is monotonically decreasing in $\theta$. Finally, $\theta$ enters $u(y) / u$ both through $u(y)$ and $u$. Intuitively, it is clear that $u(y)$ should be decreasing in $\theta$ for all $y \geq y^{*}$. That is, the direct effect of an increase in the job-finding rate for a worker of type $y$ should more than offset any secondorder effect via a change in $R(y)$. The issue is that the overall unemployment rate, $u$, is also decreasing in $\theta$. Further assumptions on $G(\cdot)$ are required to establish that $u(y) / u$ is decreasing in $\theta$ for all $y \geq y^{*}{ }^{14}$

Given assumed functional forms for the distribution functions, $F(y)$ and $G\left(y^{\prime}\right)$, and for the matching function, $m(\theta)$, and given assumed values for the exogenous parameters of

\footnotetext{
${ }^{14}$ In our simulations, when we assume that productivity shocks are iid draws from a uniform distribution, the equilibria are always unique.
} 
the model, equation (8) can be solved numerically for $\theta$. Given $\theta$, we can then recover the other equilibrium objects of the model. In fact, we can do more than this. Once we solve for equilibrium, we can compute the steady-state distributions of productivity and wages in formal-sector employment. We can then use these distributions to evaluate both the aggregate and distributional effects of labour market policy. Appendix A contains the derivations of these distributions.

\section{Simulations}

In this section, we simulate the effects of labour market policy. Specifically, we examine the effects of severance taxation and payroll taxation. We carry out two sets of numerical experiments. First, starting from our baseline case, we examine the effect of varying each of the taxes, holding the other tax at its baseline level. Second, we vary the two taxes simultaneously while holding total tax revenue constant. We examine the effects of these policies on aggregate outcomes, e.g., the unemployment rate, the size of the informal sector, the average wage and level of productivity in formal-sector jobs, and on wage inequality.

\subsection{Baseline case}

We use the following functional forms and parameter values for our simulations. First, we assume that the distribution of worker types is uniform over $[0,1]$ and that the productivity shock is likewise drawn from a standard uniform distribution. We assume the standard uniform for computational convenience, but it is not appreciably more difficult to solve the model using a flexible parametric distribution, e.g., the beta. Second, we choose our parameter values with a year as the implicit unit of time. We set $r=0.04$ as the discount rate. We normalise the flow income equivalent of leisure, $b$, to 0 . We set the parameters for the informal sector as $y_{0}=0.20, \alpha=5$ and $\delta=0.5$ and for the formal sector as $c=0.2$, $\beta=0.5$, and $\lambda=0.5$. Third, we assume a Cobb-Douglas matching function, specifically, $m(\theta)=4 \theta^{1 / 2}$. Note that the worker bargaining power parameter, $\beta$, equals the elasticity of the matching function with respect to labour market tightness. Our parameter values were chosen to produce plausible results for our baseline case in which there is a severance tax of 0.3 and a payroll tax rate of 0.5 .

Our baseline economy is meant to approximate a composite of several of the larger Latin 
American economies, in particular, Argentina, Brazil, Colombia and Mexico. Since our model is designed to examine the effects of labour market policy on the division of the workforce among unemployment, informal-sector employment and formal-sector employment, a primary target of our calibration is to produce reasonable figures for these categories. Official unemployment rates in Argentina, Brazil, Colombia and Mexico typically fall in the 5-10\% range (lower for Mexico, higher for Colombia). Our baseline unemployment rate of $7.2 \%$ is in this range and is also consistent with Gong, et al.'s (2004) estimate of a nonemployment rate for Mexican males of $6.1 \%$ (based on Mexico's Urban Employment Survey) and the $5.5 \%$ figure that Bosch (2007) uses in his calibration of the Brazilian labour market. At the other extreme, Mondragón and Peña (2008) estimate an urban unemployment rate of $13 \%$ for Colombia. In our baseline case, $38.3 \%$ of the work force is in informal-sector employment and $54.5 \%$ in formal-sector employment. This is consistent with the figures used by Satchi and Temple (2006) in their calibration of the Mexican economy as well as with Gong, et al.'s (2004) estimates. Similarly, Pratap and Quintin (2006) estimate that about 30\% of total employment in Buenos Aires and its suburbs is informal, Mondragón and Peña (2008) estimate a slightly lower fraction for Colombia, and Bosch (2007) uses $39 \%$ in his calibration for Brazil. Some authors estimate considerably higher rates of informal-sector employment, e.g., Maloney (1999) for Mexico and Kugler (1999) for Colombia, but their figures are based on a firm-size definition of informality, whereas the lower figures that we try to match are based primarily on questions that try to ascertain whether a worker's employer is paying taxes, making contributions to health care funds, etc.

There is also information about unemployment and employment duration for these countries. For example, Gong, et al. (2004) present annual transition matrices for Mexico for flows between nonemployment, informal-sector employment and formal-sector employment, and Mondragón and Peña (2008) present similar figures for Colombia. In Mexico, 84\% of the workers who are in formal-sector employment in year $t$ are also in the formal sector in year $t+1$; in Colombia, the corresponding figure is $83 \%$. Taken at face value, these figures would suggest an average duration of formal-sector employment of more than 6 years, but, of course, there are many workers who change status within each year and whose transitions are not captured in these figures. On the other hand, using quarterly data, Gong and Van Soest (2002) report that $89 \%$ of Mexican male workers employed in the formal sector in quarter $t$ are also employed in that sector in quarter $t+1$, suggesting an expected duration of formalsector employment of slightly more than two years. Given our parameterisation, we have a 
baseline employment duration of slightly less than 3.5 years, which falls between these two figures. There are also some studies that estimate hazard rates using Latin American data. For example, Galiani and Hopenhayn (2003) use data from Buenos Aires for the 1990's, a period of particularly high unemployment in Argentina. The mean survivor rates that they present are consistent with short durations, both for employment and for unemployment. Our baseline average unemployment duration of 2.69 months is roughly consistent with the figures they present.

We are also interested in matching the wage gap between the formal and informal sectors, but our model generates a larger gap than is reported in most studies. Since we treat work in the informal sector as self employment, the informal-sector wage is simply $y_{0}=0.2$. We generate an average formal-sector wage of 0.363 , so our baseline has an informal/formal wage ratio of 0.55. For Argentina, Pratap and Quintin (2006) report a ratio of about 0.77, while Bosch (2007) uses a ratio of 0.81. The figures for Colombia and Mexico are similar. We could change our baseline parameters to come closer on the informal/formal wage gap, but we have chosen to focus our effort on matching employment, unemployment, and the relative size of the informal sector as discussed above.

Our baseline taxes are $\tau=0.5$ and $s=0.3$, which generate a total tax revenue of 0.148 (equal to $37 \%$ of net output). In his calibration of the Brazilian labour market, Bosch (2007) uses $\tau=0.37$ as his payroll tax rate baseline and sets firing costs equal to 15 months of the average wage (compared to our figure, which corresponds to about 10 months of the average wage). For Colombia, Kugler and Kugler (forthcoming) indicate that the payroll tax is on the order of 40 - 60\%. Finally, Satchi and Temple (2006) assume a severance tax equal to 4 months of wages plus another 2 months for a pure firing cost. In short, our baseline payroll and severance tax figures are consistent with the levels of our composite Latin American economy.

\section{$3.2 \quad$ Numerical analysis}

We now present our numerical analysis of the model and examine the effects of varying the severance tax and the payroll tax rate. Our policy experiments are based on comparing steady states. We ignore transition path effects, although we recognise that these are also relevant for analysing the welfare effects of a policy change.

Consider first the baseline case given in row 3 of Tables 1a and 1b. With the severance 
tax of 0.3 and a payroll tax rate of 0.5 , our baseline generates a labour market tightness of $\theta=1.24$. Almost $40 \%$ of the labour force works only in the informal sector $\left(y^{*}=0.390\right)$, while about $53 \%$ of the labour force works only in the formal sector $\left(y^{* *}=0.468\right)$. The remaining $7 \%$ work in either sector as the opportunity to do so arises. The reservation productivity for the worker who is just on the margin of working in the formal sector is about 0.23 , well below $y^{*}=0.39$. Because the severance tax makes it is costly to end a match, jobs persist for some range of adverse shocks. Next, note that $R\left(y^{* *}\right)$ is slightly greater than $R\left(y^{*}\right)$. As we discussed earlier, there are two effects of $y$ on the reservation productivity. First, more productive workers have greater "upside potential"; on the other hand, more productive workers have better outside options. For this parameterisation, the second effect is slightly stronger among workers between the two cutoffs, i.e., between $y^{*}$ and $y^{* *}$, although for other parameterisations, $R(y)$ is slightly decreasing in this range. Among high-productivity workers, i.e., workers with $y \geq y^{* *}$, however, $R(y)$ is strongly increasing. This is shown in Figure 1, which presents the reservation productivity schedule for the baseline case. The next three columns of Table 1a give unemployment rates. The overall unemployment rate for the baseline case is $7.2 \%$. Among low-productivity workers, the unemployment rate is $\delta /(\alpha+\delta)=9.1 \%$ (not shown in the table since it is constant). The average unemployment rate for medium-productivity workers is much lower, reflecting the fact that these workers take both informal-sector and formal-sector jobs. Finally, the average unemployment rate for high-productivity workers is $6.3 \%$. This reflects the fact that these workers do not take up informal-sector opportunities. The last two columns of Table 1a give the employment rates for the baseline case. About $38 \%$ of the labour force is employed in the informal sector, while about $55 \%$ is employed in the formal sector.

Table $1 \mathrm{~b}$ gives average productivity for workers in the formal sector, which in the baseline case is $\bar{y}^{\prime}=0.633$, and the average wage paid to formal-sector workers, $\bar{w}=0.363$. The next column of Table $1 \mathrm{~b}$ gives net total output, i.e., the sum of outputs from the informal and formal sectors net of vacancy creation costs $(c \theta u)$, which is $Y=0.404$ for the baseline case. Tax revenue equals 0.148 in the baseline case. To the extent that tax revenues could be redistributed in a lump-sum fashion or used to finance something of value (unmodeled), the relevant output measure is net output plus tax revenues, i.e., $0.404+0.148=0.552$. Finally, we report expected durations for unemployment, vacancies, and employment in the formal sector. The unemployment duration figure is for high-productivity workers, i.e., workers who only accept formal-sector employment. These figures are given in months and are 2.69, 3.35, 
and 40.55 , respectively.

We also show the distributions of formal-sector productivity and wages. Figure 2 presents the distribution of types $(y)$, and current productivities $\left(y^{\prime}\right)$ in the formal sector for the baseline case. The density of $y$ is the contaminated one; i.e., it incorporates the different job-finding and job-losing experiences of the various worker types. Since no worker's current productivity can exceed his or her type, the distribution of $y$ necessarily first-order stochastically dominates that of $y^{\prime}$. Both the severance tax and the payroll tax compress the distribution of types in the formal sector. The severance tax shifts the density of current productivity to the left, reflecting the decrease in reservation productivities. The payroll tax shifts the density of $y^{\prime}$ to the right, reflecting the upward shift in the reservation productivity schedule. Thus, if tax revenue were held constant, increasing $s$ and decreasing $\tau$ would shift the density of $y^{\prime}$ to the left. Figure 3 presents the distributions of current productivity and wages. Since the surplus is shared between the firm and the worker, the density of $y^{\prime}$ first-order stochastically dominates that of $w$. In addition, as illustrated in Figure 3 for the baseline case, both taxes compress the wage distribution.

The other rows of Tables $1 \mathrm{a}$ and $\mathrm{b}$ show the effects of varying the severance tax, $s$, and the payroll tax rate, $\tau$. These tables allow us to present the effects of each tax separately. Tables $2 \mathrm{a}$ and $\mathrm{b}$, which we discuss next, consider the effects of varying the two taxes holding tax revenue fixed. To discuss the latter effects, it is helpful to first see how each tax operates when the other tax is fixed. Comparing rows 1,3 , and 5 of Tables $1 \mathrm{a}$ and b, we can see the effect of increasing the severance tax holding the rate of payroll taxation fixed. An increase in the severance tax makes vacancy creation less attractive, leads worker-firm pairs to sustain relatively unproductive matches, and shifts employment from the formal to the informal sector. On the other hand, an increase in $s$ decreases overall unemployment. The increase in expected employment duration among formal-sector workers outweighs the reduction in the job arrival rate. Since the reduction in unemployment associated with formal-sector jobs outweighs the effect of the increase in the number of workers in the high-unemployment informal sector, the overall unemployment rate falls. This fall in the overall unemployment rate is more than offset by the decrease in vacancy creation, so labour market tightness falls. While the unemployment effects of the severance tax make it seem attractive, this policy leads to strong negative effects on formal-sector productivity via the downward shift in $R(y)$. Wages in the formal sector fall, as does net output. Tax receipts first increase in $s$ but then decrease. There are two reasons that tax receipts can fall as $s$ increases - (i) there are fewer 
formal-sector matches to tax and (ii) worker-firm matches are increasingly less productive on average, so payroll tax revenues fall. Finally, the increases in the durations of formalsector unemployment and employment are evident in Table 1b, and, not surprisingly, we see a decrease in vacancy duration.

The effects of varying the payroll tax rate holding the severance tax fixed can be seen in rows 2, 3, and 4 of Tables $1 \mathrm{a}$ and $\mathrm{b}$. We consider payroll taxes ranging from zero to $100 \%$. Increasing the payroll tax reduces $\theta$ by making formal-sector vacancy creation less attractive. The payroll tax also has compositional effects. The fraction of workers who never take formal-sector jobs $\left(y<y^{*}\right)$ increases substantially with $\tau$, and the fraction who only take formal-sector jobs $\left(y>y^{* *}\right)$ decreases substantially with $\tau$. The payroll tax has a stronger effect on the unemployment value of high-productivity workers than on that of mediumproductivity workers, so $y^{* *}$ increases by more than $y^{*}$ with $\tau$. This means that the fraction of workers who would take a job in either sector increases with $\tau$. In contrast to the effect of the severance tax, a payroll tax decreases job duration by shifting up the reservation productivity schedule. The fact that both labour market tightness and expected formalsector job duration decrease implies that unemployment increases among both medium- and high-productivity workers. Consistent with the compositional change and the shift in the reservation productivity schedule, average formal-sector productivity rises. Nonetheless, the average formal-sector wage falls, as does net output. Tax receipts increase with $\tau$ at a decreasing rate. There are fewer matches to tax as $\tau$ increases, but this effect is offset to some extent by the fact that the matches that are taxed are increasingly more productive.

Interestingly, net output plus total tax revenue increases in the payroll tax rate. This is partly a second-best result. The severance tax leads to inefficiently long employment durations, and increasing $\tau$ works against this effect. However, increasing the payroll tax (at least over some range) would be beneficial even were $s=0$. There is an inefficiency in the no-tax case that results from the interaction between worker heterogeneity and the informal/formal dichotomy. The marginal workers (types $y^{*}$ and $y^{* *}$ ) are making incorrect decisions from a social planner's perspective. We have made a strong assumption about the matching process, namely, that increasing the size of the unemployment pool does not make it more difficult for an individual worker to find an informal-sector opportunity. This assumption - or, more generally, the assumption that congestion effects are weaker in the informal sector than in the formal sector - means that marginal workers are too eager to wait for formal-sector jobs (equivalently, not eager enough to wait for informal-sector 
opportunities). That is, these workers fail to internalise the congestion externality that they impose on other workers. In short, given our assumptions about the matching process, the social planner would expand the size of the informal sector in order to reduce congestion in the formal-sector market. This is precisely what taxes that are imposed only on formal-sector matches do. Of course, in addition to this beneficial effect, taxation also has distortionary effects. The distortionary effects of severance taxation are stronger than those of the payroll tax, and this is why, for this parameterisation, an increase in $\tau$ increases welfare but an increase in $s$ does not.

Tables $2 \mathrm{a}$ and $2 \mathrm{~b}$ show the effect of changing the severance tax, $s$, and the payroll tax rate, $\tau$, holding tax revenue fixed at the baseline level of 0.148 . Reading down the table, we raise $s$ and adjust $\tau$ accordingly. Both taxes make vacancy creation less attractive, but the severance tax has the dominant effect for our parameterisation. Labour market tightness, $\theta$, decreases as $s$ rises and $\tau$ falls. The two cutoff values $y^{*}$ and $y^{* *}$ increase with both $s$ and $\tau$, but with tax revenue constant, the effect of raising $s$ dominates that of lowering $\tau$, and both cutoff values rise as we go down Table $2 \mathrm{a}$. That is, the fraction of workers who never take formal-sector jobs $\left(y<y^{*}\right)$ increases, and the fraction who only take formal-sector jobs $\left(y>y^{* *}\right)$ decreases as $s$ rises and $\tau$ falls. Because the severance tax makes it more costly to end matches, increases in $s$ shift the reservation productivity schedule down. However, a payroll tax increase, ceteris paribus, would shift the reservation productivity schedule up. Thus, as $s$ increases and $\tau$ decreases, the two effects reinforce each other and $R\left(y^{*}\right)$ and $R\left(y^{* *}\right)$ decrease substantially. There is also some decrease in the unemployment rates for mediumand high-productivity workers. This again reflects the fact that the effect of increasing job duration outweighs the reduction in the job arrival rate. The overall unemployment rate falls. Since an increase in $s$ and a decrease in $\tau$ both reduce formal-sector productivity, $\bar{y}^{\prime}$ falls. Formal sector wages fall, as does net output. The changes in unemployment duration are also consistent with the severance tax having a stronger effect that the payroll tax. Finally, since increases in the two taxes have opposite effects on employment duration, when the severance tax rises and the payroll tax rate falls, there is a large increase in employment duration. Once the severance tax goes above $s=0.3$, tax revenues fall holding $\tau$ fixed at its baseline level. That is, keeping tax revenues constant while raising the severance tax above its baseline level requires an increase in the payroll tax rate. Since the severance tax effects are dominant, the unemployment rate continues to fall as $s$ increases, but all other measures of labour market performance continue to deteriorate. 
Table 3 presents several measures of wage inequality for the formal sector using the same tax rates as in Tables $2 \mathrm{a}$ and $2 \mathrm{~b}$, i.e., holding tax revenue constant. We ignore inequality in the informal sector because we have assumed a fixed informal wage. While the figures in Table 3 are thus not directly comparable to reported data, they do give an idea of the effect that varying the taxes has on wage inequality. For our baseline parameterisation, we find a 90/10 ratio of about 2.0 for the formal sector. Comparing the 90/50 ratio (1.35) to the $50 / 10$ ratio (1.50) indicates that there is more inequality in the bottom of the formal-sector wage distribution. As we move down Table 3, the severance tax increases. This reduces wage inequality substantially. A reduction in inequality is evidenced in both the top and the bottom of the wage distribution, although there is a larger drop in the 50/10 ratio than in the 90/50 ratio. The effect on overall wage inequality is confirmed in the last column of Table 3, which reports the standard deviation of log wages.

\section{Conclusions}

In this paper, we build a search and matching model to analyse the effect of labour market policies in an economy with a significant informal sector. In light of the empirical evidence for many developing countries, especially in Latin American, we model an economy where workers operate as self employed in the informal sector. Our model is a substantial extension of Mortensen and Pissarides (1994) that allows for imperfect sorting of workers between the formal and informal sectors. Depending on their productivity levels, some workers only work in the formal sector, others only work in the informal sector, and an intermediate group of workers take jobs in either sector.

We solve our model numerically and analyse the effects of two labour market policies, a severance tax and a payroll tax. A severance tax greatly increases average employment duration in the formal sector, reduces overall unemployment, reduces the number of formalsector workers, and reduces the number of workers who accept any type of offer (formal or informal). A payroll tax reduces average employment duration in the formal sector, greatly reduces the number of formal-sector workers, and significantly increases the size of the informal sector and the number of workers accepting any type of offer. Total unemployment rises. The two policies also have different effects on the distributions of productivity and wages in the formal sector. The severance tax decreases average productivity, while the payroll tax increases it, but under both policies, net output falls. 


\section{References}

[1] Amaral, P. and Quintin, E. (2006). 'A competitive model of the informal sector', Journal of Monetary Economics, vol. 53(7) (October), pp. 1541-1553.

[2] Benhabib, J., Rogerson, R. and Wright, R. (1991). 'Homework in macroeconomics: Household production and aggregate fluctuations', Journal of Political Economy, vol. 99(6) (January), pp. 1166-1187.

[3] Boeri, T. and Garibaldi, P. (2007). 'Shadow sorting', in (J. Frankel and C. Pissarides, eds.) NBER International Seminar on Macroeconomics 2005, Cambridge, Massachusetts:MIT Press.

[4] Bosch, M. (2007). 'Job creation and job destruction in the presence of informal markets', mimeo.

[5] Dolado, J., Jansen, M. and Jimeno, J. (2007). 'A positive analysis of targeted employment legislation', BE Journal of Macroeconomics (Topics), vol. 7(1).

[6] Fugazza, M. and Jacques, J. (2004). 'Labor market institutions, taxation and the underground economy', Journal of Public Economics, vol. 88(1) (January), pp. 395-418.

[7] Galiani, S. and Hopenhayn, H. (2003). 'Duration and risk of unemployment in Argentina', Journal of Development Economics, vol 71(1) (June), pp. 199-212.

[8] Gollin, D., Parente, S. and Rogerson, R. (2004). 'Farm work, home work and international productivity differences', Review of Economic Dynamics, vol. 7(4) (October), pp. 827-850.

[9] Gong, X. and van Soest, A. (2002). 'Wage differentials and mobility in the urban labour market: A panel data analysis for Mexico', Labour Economics, vol. 9(4) (September), pp. 513-529.

[10] Gong, X., van Soest, A. and Villagomez, E. (2004). 'Mobility in the urban labor market: A panel data analysis for Mexico', Economic Development and Cultural Change, vol. 53(1) (October), pp. 1-36. 
[11] Heckman, J. and Pagés, C., eds. (2004). Law and Employment: Lessons from Latin America and the Caribbean, Chicago: NBER and University of Chicago Press.

[12] Kolm, A. and Larsen, B. (2004). 'Does tax evasion affect unemployment and educational choice?', IFAU Working Paper, 2004:4.

[13] Kugler, A. (1999). 'The impact of firing costs on turnover and unemployment: Evidence from the Colombian labor market reforms', International Tax and Public Finance, vol. 6(3) (August), pp. 389-410.

[14] Kugler, A. and Kugler, M. (forthcoming). 'Labor market effects of payroll taxes in developing countries: Evidence from Colombia', Economic Development and Cultural Change.

[15] Laing, D., Park, C. and Wang, P. (2005). 'A modified Harris-Todaro model for ruralurban migration for China', in (F. Kwan and E. Yu, eds.) Critical Issues in China's Growth and Development, Ashgate Publishing Limited, pp. 245-64.

[16] Masatlioglu, W. and Rigolini, J. (2006). 'Informality traps', mimeo.

[17] Maloney, W. (1999). 'Does informality imply segmentation in urban labor markets? Evidence from sectoral transitions in Mexico', World Bank Economic Review, vol. 13(2), pp. 275-302.

[18] Maloney, W. (2004). 'Informality revisited', World Development, vol. 32(7) (July), pp. 1159-1178.

[19] Mondragón Velez, C. and Peña Pargas, X. (2008). 'Business ownership and selfemployment in developing economies: The Colombian case', CEDE Working Paper 2008-03, Universidad de los Andes.

[20] Mortensen, D. and Pissarides, C. (1994). 'Job creation and job destruction in the theory of unemployment', Review of Economic Studies, vol. 61(3) (July), pp. 397-415.

[21] Mortensen, D. and Pissarides, C. (1999). 'Job reallocation, employment fluctuations and unemployment', in (J. B. Taylor and M. Woodford, eds.) Handbook of Macroeconomics, Volume I, Amsterdam: North Holland. 
[22] Mortensen, D. and Pissarides, C. (2003). 'Taxes, subsidies and equilibrium labor market outcomes', in (E. S. Phelps, ed.) Designing Inclusion: Tools to Raise Low-End Pay and Employment in Private Enterprise, Cambridge: Cambridge University Press.

[23] Parente, S., Rogerson, R. and Wright, R. (2000). 'Homework in development economics: Household production and the wealth of nations', Journal of Political Economy, vol. 108(4) (August), pp. 680-687.

[24] Pratap, S. and Quintin, E. (2006). 'Are labor markets segmented in developing countries? A semiparametric approach', European Economic Review, vol. 50(7) (October), pp. $1817-1841$.

[25] Satchi, M. and Temple, J. (2006). 'Growth and labour markets in developing countries', CEPR Discussion Paper No. 5515.

[26] Schneider, F. and Enste, D. (2000). 'Shadow economies: Sizes, causes, consequences', Journal of Economic Literature, vol. 38(1) (March), pp. 77-114.

[27] Zenou, Y. (2008). 'Job search and mobility in developing countries: Theory and policy implications', Journal of Development Economics, vol. 86(2) (June), pp. 336-355. 


\section{Appendix A: Derivation of the equilibrium produc- tivity and wage distributions for the formal sector}

We start with the derivation of the joint distribution of $\left(y^{\prime}, y\right)$ across workers employed in the formal sector. Once we compute this joint distribution (and the corresponding marginals), we can find the distribution of wages in the formal sector.

To find the distribution of $\left(y^{\prime}, y\right)$ across workers employed in the formal sector, we use

$$
h\left(y^{\prime}, y\right)=h\left(y^{\prime} \mid y\right) h(y)
$$

Here $h\left(y^{\prime}, y\right)$ is the joint density of current productivity and worker type, $h\left(y^{\prime} \mid y\right)$ is the conditional density of current productivity given worker type, and $h(y)$ is the marginal density of worker type across workers employed in the formal sector. It is relatively easy to compute $h(y)$. Let $E$ denote "employed in the formal sector." Then by Bayes' Law,

$$
h(y)=\frac{P[E \mid y] f(y)}{P[E]}=\frac{n_{1}(y) f(y)}{\int n_{1}(y) f(y) d y},
$$

where from equations (5) to (7),

$$
\begin{aligned}
n_{1}(y) & =0 & \text { for } y \leq y^{*} \\
& =\frac{\delta m(\theta) G(y)}{\lambda(\delta+\alpha) G(R(y))+\delta m(\theta) G(y)} & \text { for } y^{*} \leq y<y^{* *} \\
& =\frac{m(\theta) G(y)}{\lambda G(R(y))+m(\theta) G(y)} & \text { for } y \geq y^{* *} .
\end{aligned}
$$

Next, we need to find $h\left(y^{\prime} \mid y\right)$. Consider a worker of type $y$ who is employed in the formal sector. The worker's match starts at productivity $y$; later, a shock (or shocks) may change the match productivity. Let $N$ denote the number of shocks this worker has experienced to date (in the current spell of employment in the formal sector). Since we are considering a worker who is employed in the formal sector, we know that none of these shocks has resulted in a productivity realisation below $R(y)$.

If $N=0$, then $y^{\prime}=y$ with probability 1 . If $N=1,2, \ldots$, then $y^{\prime}$ is a draw from $\frac{g\left(y^{\prime}\right)}{G(y)-G(R(y))}$ for $R(y) \leq y^{\prime} \leq y$. Summarising, we have

$$
\begin{aligned}
P\left[y^{\prime}\right. & =y \mid y]=P[N=0] \\
h\left(y^{\prime} \mid y\right) & =\left(\frac{g\left(y^{\prime}\right)}{G(y)-G(R(y))}\right)(1-P[N=0]) \text { for } R(y) \leq y^{\prime}<y .
\end{aligned}
$$


We thus need to find $P[N=0]$ for a worker of type $y$ who is currently employed in the formal sector.

To do this, we first condition on elapsed duration. Consider a worker of type $y$ whose elapsed duration of employment in her current formal sector job is $t$. Let $N_{t}$ be the number of shocks this worker has realised to date. Shocks arrive at rate $\lambda$. However, as the worker is still employed, we know that none of the realisations of these shocks was below $R(y)$. Thus, $N_{t}$ is Poisson with parameter $\lambda\left(1-\frac{G(R(y)}{G(y)}\right) t$, and $P\left[N_{t}=0\right]=\exp \left\{-\lambda\left(1-\frac{G(R(y))}{G(y)}\right) t\right\}$. To find $P[N=0]$, we integrate $P\left[N_{t}=0\right]$ against the density of elapsed durations. A worker of type $y$ exits formal sector employment at Poisson rate $\lambda \frac{G(R(y))}{G(y)}$; equivalently, the distribution of completed durations for a worker of this type is exponential with parameter $\lambda \frac{G(R(y))}{G(y)}$. The exponential has the convenient property that the distributions of completed and elapsed durations are the same. Thus,

$$
P[N=0]=\int_{0}^{\infty} \exp \left\{-\lambda\left(1-\frac{G(R(y))}{G(y)}\right) t\right\} \lambda \frac{G(R(y))}{G(y)} \exp \left\{-\lambda \frac{G(R(y))}{G(y)} t\right\} d t=\frac{G(R(y))}{G(y)}
$$

for a worker of type $y$.

Thus, the probability that a worker of type $y$ is working to her potential when she is employed in a formal sector job (i.e., that $y^{\prime}=y$ ) is

$$
P\left[y^{\prime}=y \mid y\right]=\frac{G(R(y))}{G(y)} .
$$

The density of $y^{\prime}$ across all other values that are consistent with continued formal-sector employment for a type $y$ worker is

$$
h\left(y^{\prime} \mid y\right)=\frac{g\left(y^{\prime}\right)}{G(y)-G(R(y))}\left(1-\frac{G(R(y))}{G(y)}\right)=\frac{g\left(y^{\prime}\right)}{G(y)} \text { for } R(y) \leq y^{\prime}<y .
$$

The conditional distribution of $y^{\prime}$ given $y$ thus consists of a smooth density for $R(y) \leq y^{\prime}<y$ coupled with a mass point at $y^{\prime}=y$.

Given the marginal density for $y$ and the conditional density, $h\left(y^{\prime} \mid y\right)$, we thus have the joint density, $h\left(y^{\prime}, y\right)$, which is defined for for $y^{*} \leq y \leq 1$ and $R(y) \leq y^{\prime} \leq y$, i.e., for the $\left(y^{\prime}, y\right)$ combinations that are consistent with formal-sector employment. The final steps are to compute the densities of productivity in formal-sector employment (i.e., the marginal density of $\left.y^{\prime}\right)$ and of formal-sector wages. The density of $y^{\prime}$ is computed as $h\left(y^{\prime}\right)=\int h\left(y^{\prime} \mid y\right) h(y) d y=$ $\int h\left(y^{\prime}, y\right) d y$. 
To derive the distribution of wages across formal-sector employment, we use $m(w)=$ $\int m(w \mid y) h(y) d y$. We thus need the conditional distribution of wages given worker type, i.e., $m(w \mid y)$. Recall that

$$
\begin{aligned}
w(y) & =\frac{\beta(y-\lambda s)+(1-\beta)(1+\tau) r U(y)}{1+\tau} \\
w\left(y^{\prime}, y\right) & =\frac{\beta\left(y^{\prime}+r s\right)+(1-\beta)(1+\tau) r U(y)}{1+\tau} .
\end{aligned}
$$

Worker $y$ receives wage $w(y)$ up to the time that the first shock to match productivity is realised. After that, the worker's wage is given by $w\left(y^{\prime}, y\right)$. The probability that worker $y$ receives $w(y)$ is thus $P[N=0]=\frac{G(R(y))}{G(y)}$. The density of $y^{\prime}$ conditional on $y$ is $\frac{g\left(y^{\prime}\right)}{G(y)}$ for $y^{\prime} \in[R(y), y)$. Inverting $w\left(y^{\prime}, y\right)$ implies that the density of $w\left(y^{\prime}, y\right)$ is

$$
\left(\frac{1+\tau}{\beta}\right) \frac{g\left(\left(\frac{1+\tau}{\beta}\right) w-r s-(1-\beta)(1+\tau) r U(y)\right)}{G(y)} \text { for } w \in[w(R(y), y), w(y, y)]
$$

Summarising, conditional on $y$ we have

$$
\begin{aligned}
P[w & =w(y)]=\frac{G(R(y))}{G(y)} \\
m(w \mid y) & =\left(\frac{1+\tau}{\beta}\right) \frac{g\left(\left(\frac{1+\tau}{\beta}\right) w-r s-(1-\beta)(1+\tau) r U(y)\right)}{G(y)} \text { for } w \in[w(R(y)), w(y, y)) .
\end{aligned}
$$

Again, the conditional distribution of wages given worker type $y$ is a continuous density over $[w(R(y)), w(y, y))$ coupled with a mass point at $w(y)$. Unless $s=0$, this mass point will be located below $w(y, y) \cdot{ }^{15}$

The final step is to integrate the distribution of wages conditional on worker type against the density of $y$ among workers in formal-sector jobs. Note that although the distributions of current productivity and wages given $y$ both have mass points, these mass points are smoothed away when we integrate against $h(y)$.

\footnotetext{
${ }^{15}$ In our simulations, when we assume that productivity shocks are iid draws from a standard uniform distribution, these expressions simplify considerably. Specifically, $P\left[y^{\prime}=y \mid y\right]=R(y) / y$ and $h\left(y^{\prime} \mid y\right)=1 / y$ for $R(y) \leq y^{\prime}<y$. Similarly, $P[w=w(y)]=R(y) / y$ and $m(w \mid y)=\left(\frac{1+\tau}{\beta}\right) \frac{1}{y}$ for $w \in[w(R(y)), w(y, y))$.
} 
Table 1a: Effects of Varying $s$ and $\tau$

\begin{tabular}{|c|c|c|c|c|c|c|c|c|c|c|c|}
\hline \multicolumn{2}{|c|}{ Taxes } & \multicolumn{9}{|c|}{} & \multicolumn{3}{c|}{ u rates by type } & \multicolumn{2}{c|}{ employment } \\
\hline$s$ & $\tau$ & $\theta$ & $y^{*}$ & $y^{* *}$ & $R\left(y^{*}\right)$ & $R\left(y^{* *}\right)$ & med & high & total & $n_{0}$ & $n_{1}$ \\
\hline 0.1 & 0.5 & 1.59 & 0.317 & 0.398 & 0.263 & 0.280 & 0.041 & 0.069 & 0.074 & 0.321 & 0.605 \\
\hline 0.3 & 0 & 1.40 & 0.288 & 0.336 & 0.126 & 0.129 & 0.029 & 0.058 & 0.066 & 0.276 & 0.658 \\
\hline $\mathbf{0 . 3}$ & $\mathbf{0 . 5}$ & $\mathbf{1 . 2 4}$ & $\mathbf{0 . 3 9 0}$ & $\mathbf{0 . 4 6 8}$ & $\mathbf{0 . 2 2 8}$ & $\mathbf{0 . 2 3 4}$ & $\mathbf{0 . 0 3 6}$ & $\mathbf{0 . 0 6 3}$ & $\mathbf{0 . 0 7 2}$ & $\mathbf{0 . 3 8 3}$ & $\mathbf{0 . 5 4 5}$ \\
\hline 0.3 & 1.0 & 1.08 & 0.486 & 0.599 & 0.324 & 0.333 & 0.041 & 0.069 & 0.076 & 0.488 & 0.436 \\
\hline 0.5 & 0.5 & 0.97 & 0.444 & 0.522 & 0.175 & 0.170 & 0.030 & 0.055 & 0.069 & 0.428 & 0.503 \\
\hline
\end{tabular}

Table 1b: Effects on Durations of Varying $s$ and $\tau$ without keeping tax revenue constant

\begin{tabular}{|c|c|c|c|c|c|c|c|c|}
\hline \multicolumn{2}{|c|}{ Taxes } & \multicolumn{2}{|c|}{ formal sector } & output & Tax & \multicolumn{2}{c|}{ Durations (months) - formal sector } \\
\hline$s$ & $\tau$ & $\bar{y}^{\prime}$ & $\bar{w}$ & net $Y$ & Revenue & unemployment & vacancy & employment \\
\hline 0.1 & 0.5 & 0.651 & 0.384 & 0.434 & 0.139 & 2.38 & 3.79 & 32.01 \\
\hline 0.3 & 0 & 0.568 & 0.495 & 0.411 & 0.056 & 2.54 & 3.55 & 43.15 \\
\hline $\mathbf{0 . 3}$ & $\mathbf{0 . 5}$ & $\mathbf{0 . 6 3 3}$ & $\mathbf{0 . 3 6 3}$ & $\mathbf{0 . 4 0 4}$ & $\mathbf{0 . 1 4 8}$ & $\mathbf{2 . 6 9}$ & $\mathbf{3 . 3 5}$ & $\mathbf{4 0 . 5 5}$ \\
\hline 0.3 & 1.0 & 0.691 & 0.297 & 0.383 & 0.169 & 2.89 & 3.11 & 39.36 \\
\hline 0.5 & 0.5 & 0.581 & 0.343 & 0.364 & 0.143 & 3.05 & 2.95 & 54.55 \\
\hline
\end{tabular}


Table 2a: Effects of Varying $s$ and $\tau$ with tax revenue constant at 0.148

\begin{tabular}{|c|c|c|c|c|c|c|c|c|c|c|c|}
\hline \multicolumn{2}{|c|}{ Taxes } & \multicolumn{9}{|c|}{} & \multicolumn{3}{c|}{ u rates by type } & \multicolumn{2}{c|}{ employment } \\
\hline$s$ & $\tau$ & $\theta$ & $y^{*}$ & $y^{* *}$ & $R\left(y^{*}\right)$ & $R\left(y^{* *}\right)$ & med & high & total & $n_{0}$ & $n_{1}$ \\
\hline 0 & 0.66 & 1.76 & 0.300 & 0.394 & 0.300 & 0.327 & 0.044 & 0.072 & 0.075 & 0.314 & 0.611 \\
\hline 0.1 & 0.57 & 1.57 & 0.330 & 0.416 & 0.276 & 0.294 & 0.041 & 0.070 & 0.074 & 0.335 & 0.590 \\
\hline 0.2 & 0.52 & 1.40 & 0.359 & 0.440 & 0.251 & 0.263 & 0.039 & 0.066 & 0.073 & 0.358 & 0.569 \\
\hline $\mathbf{0 . 3}$ & $\mathbf{0 . 5 0}$ & $\mathbf{1 . 2 4}$ & $\mathbf{0 . 3 9 0}$ & $\mathbf{0 . 4 6 8}$ & $\mathbf{0 . 2 2 8}$ & $\mathbf{0 . 2 3 4}$ & $\mathbf{0 . 0 3 6}$ & $\mathbf{0 . 0 6 3}$ & $\mathbf{0 . 0 7 2}$ & $\mathbf{0 . 3 8 3}$ & $\mathbf{0 . 5 4 5}$ \\
\hline 0.4 & 0.51 & 1.10 & 0.421 & 0.500 & 0.205 & 0.206 & 0.034 & 0.060 & 0.071 & 0.409 & 0.520 \\
\hline 0.5 & 0.58 & 0.94 & 0.461 & 0.545 & 0.192 & 0.187 & 0.032 & 0.056 & 0.070 & 0.446 & 0.484 \\
\hline
\end{tabular}

Table 2b: Effects on Durations of Varying $s$ and $\tau$ with tax revenue constant at 0.148

\begin{tabular}{|c|c|c|c|c|c|c|c|}
\hline \multicolumn{2}{|c|}{ Taxes } & \multicolumn{2}{c|}{ formal } & \multicolumn{2}{c|}{ output } & \multicolumn{3}{c|}{ Durations (months) - formal sector } \\
\hline$s$ & $\tau$ & $\bar{y}^{\prime}$ & $\bar{w}$ & net $Y$ & unemployment & vacancy & employment \\
\hline 0 & 0.66 & 0.659 & 0.367 & 0.439 & 2.26 & 3.98 & 28.76 \\
\hline 0.1 & 0.57 & 0.657 & 0.372 & 0.432 & 2.40 & 3.76 & 31.97 \\
\hline 0.2 & 0.52 & 0.649 & 0.371 & 0.420 & 2.54 & 3.55 & 35.82 \\
\hline $\mathbf{0 . 3}$ & $\mathbf{0 . 5 0}$ & $\mathbf{0 . 6 3 3}$ & $\mathbf{0 . 3 6 3}$ & $\mathbf{0 . 4 0 4}$ & $\mathbf{2 . 6 9}$ & $\mathbf{3 . 3 5}$ & $\mathbf{4 0 . 5 5}$ \\
\hline 0.4 & 0.51 & 0.614 & 0.353 & 0.386 & 2.86 & 3.15 & 46.44 \\
\hline 0.5 & 0.58 & 0.594 & 0.331 & 0.363 & 3.09 & 2.91 & 53.66 \\
\hline
\end{tabular}

Table 3: Inequality Measures for the Formal Sector:

Tax revenue constant at 0.148

\begin{tabular}{|c|c|c|c|c|c|}
\hline \multicolumn{2}{|c|}{ Taxes } & \multicolumn{3}{|c|}{ formal sector } & std. dev \\
\hline$s$ & $\tau$ & $\mathrm{p} 90 / \mathrm{p} 10$ & $\mathrm{p} 90 / \mathrm{p} 50$ & $\mathrm{p} 50 / \mathrm{p} 10$ & log wages \\
\hline 0 & 0.66 & 2.481 & 1.431 & 1.733 & 0.328 \\
\hline 0.1 & 0.57 & 2.365 & 1.409 & 1.678 & 0.311 \\
\hline 0.2 & 0.52 & 2.213 & 1.381 & 1.603 & 0.289 \\
\hline $\mathbf{0 . 3}$ & $\mathbf{0 . 5 0}$ & $\mathbf{2 . 0 2 5}$ & $\mathbf{1 . 3 4 6}$ & $\mathbf{1 . 5 0 4}$ & $\mathbf{0 . 2 5 8}$ \\
\hline 0.4 & 0.51 & 1.818 & 1.302 & 1.397 & 0.220 \\
\hline 0.5 & 0.58 & 1.604 & 1.241 & 1.292 & 0.173 \\
\hline
\end{tabular}


Fig. 1

Reservation Productivity $\mathrm{R}(\mathrm{y})$ $s=0.3, \operatorname{tau}=0.5$

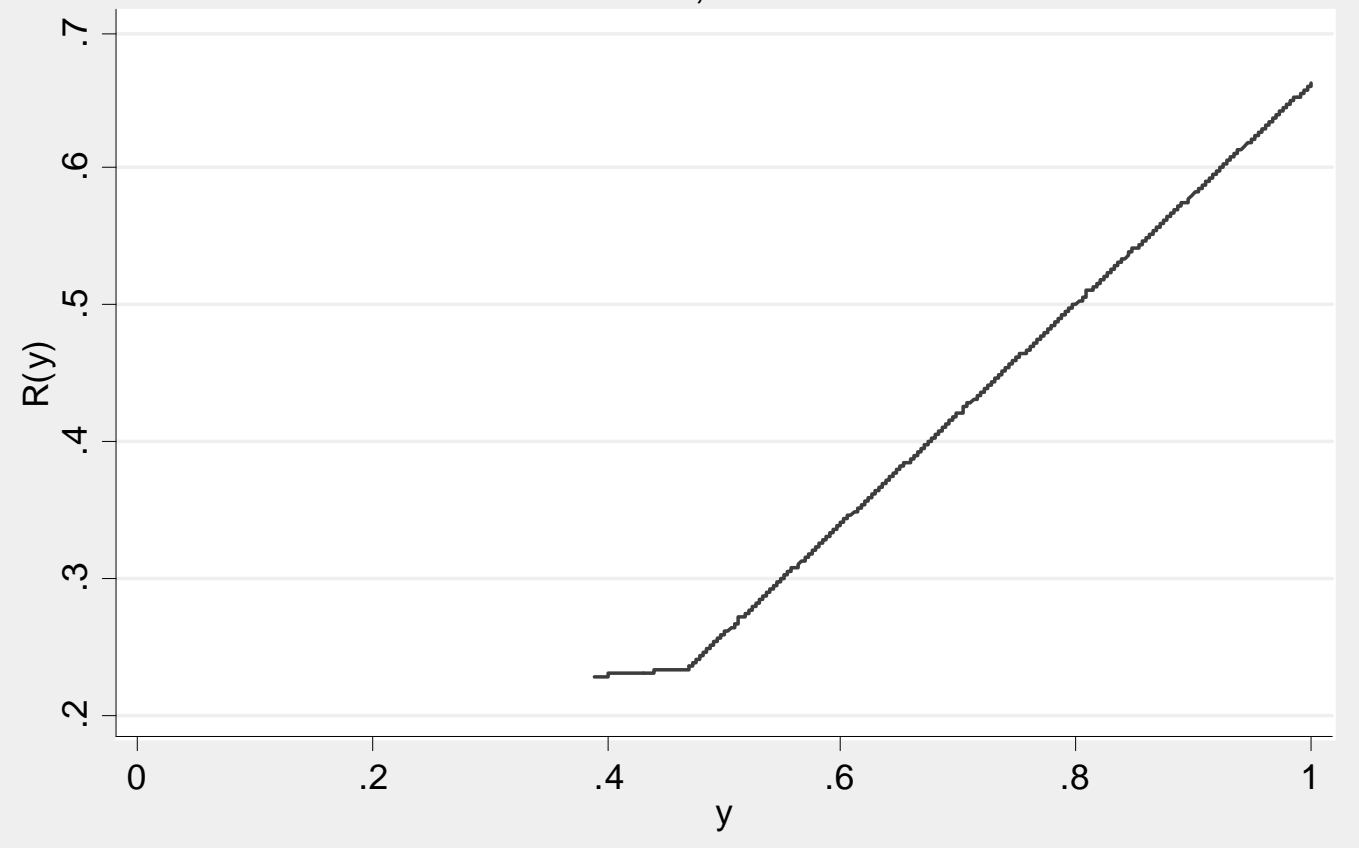


Fig. 2

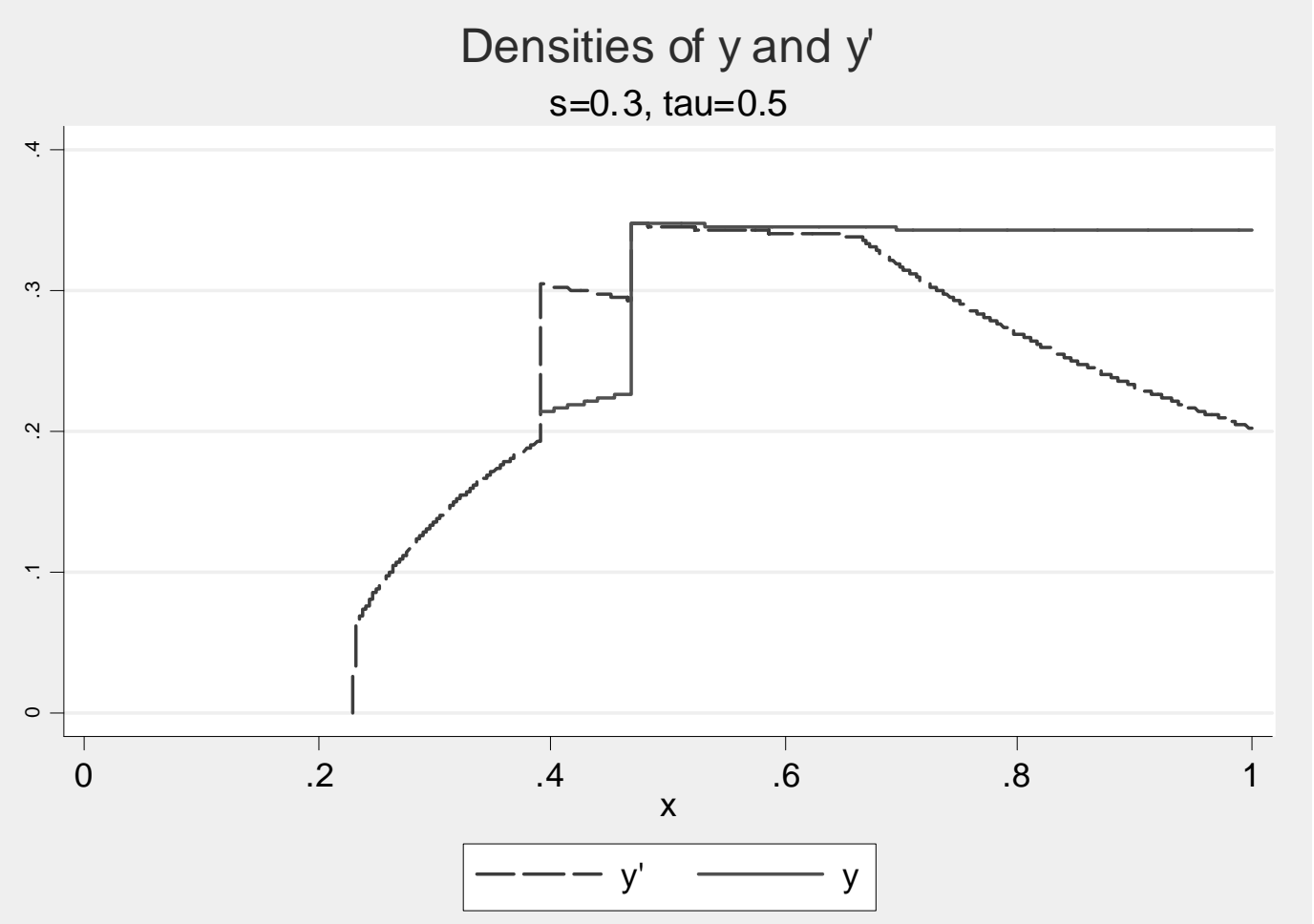


Fig. 3

Densities of $y^{\prime}$ and $w\left(y^{\prime}, y\right)$ $s=0.3, \operatorname{tau}=0.5$

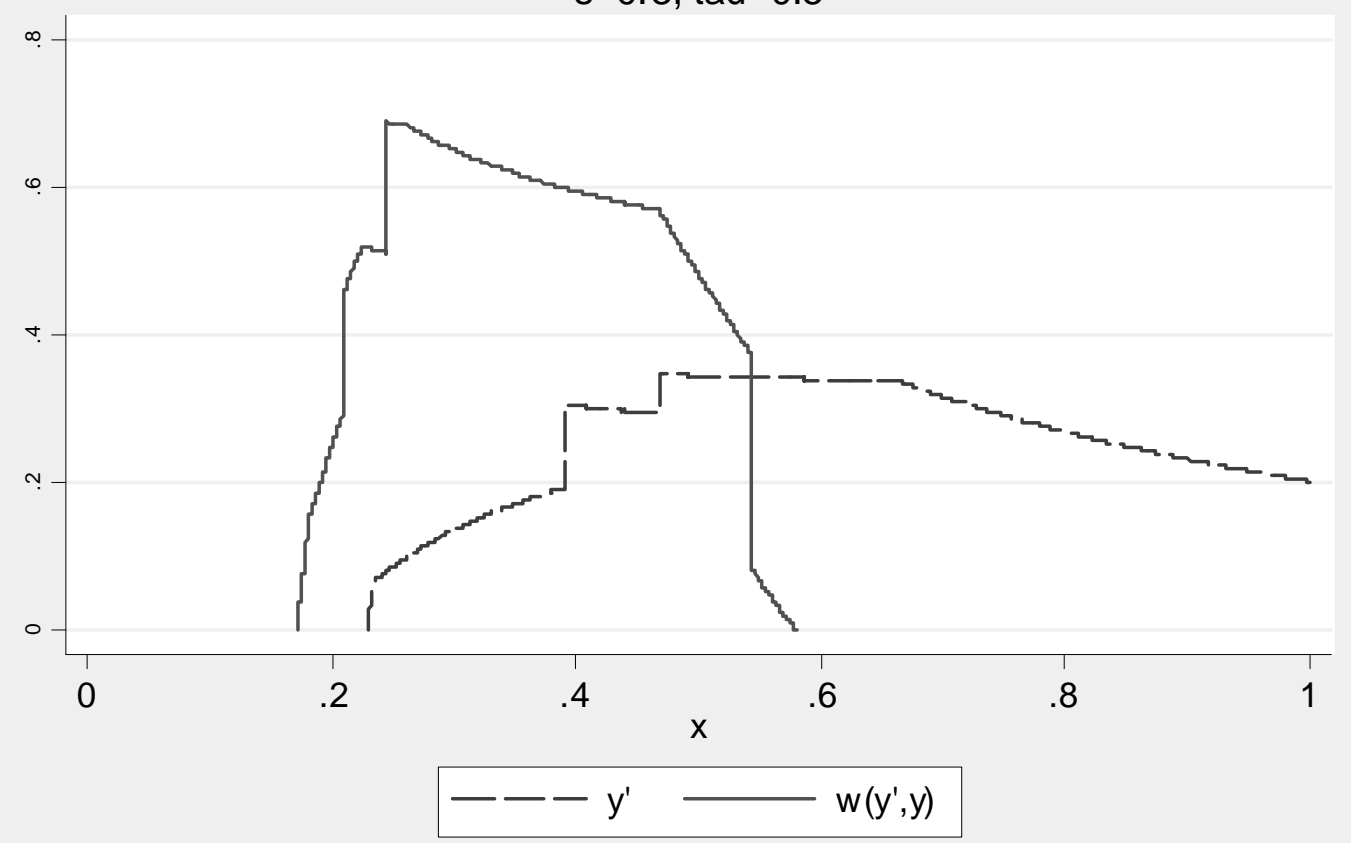

